\title{
Arta (Calligonum Comosum, L'Her.) Shoot Extracts: Bio-Mediator in Silver Nanoparticles Formation and Antimycotic Potential
}

\author{
Afrah E. Mohammed \\ Department of Biology, Faculty of Science, Princess Nourah bint Abdulrahman University, Riyadh 11671, Saudi Arabia. \\ Corresponding author. E-mail: farhati@hotmail.com
}

Received: Jun. 26, 2016; Accepted: Jul. 25, 2016; Published: Aug. 1, 2016.

Citation: Afrah E. Mohammed, Arta (Calligonum Comosum, L'Her.) Shoot Extracts: Bio-Mediator in Silver Nanoparticles Formation and Antimycotic Potential. Nano Biomed. Eng., 2016, 8(3): 128-135.

DOI: $10.5101 /$ nbe.v8i3.p128-135.

\begin{abstract}
Environmentally friendly green synthesis of nanomaterial has a very significant part in nanotechnology. In the present research, the synthesis of silver nanoparticles (AgNPs) was established by treating silver ions with the aqueous extract of Calligonum comosum green shoots at room temperature. AgNPs formation was firstly detected by the colour change of mixed extract (plant extract and $\mathrm{AgNO}_{3}$ ). Further characterization was done by ultraviolet, (UV)-Vis spectrophotometer, transmission electron microscopy (TEM), scanning electron microscopy (SEM), zeta potential and fourier transform infrared spectroscopy (FTIR). The peak values for UV-VIS- spectroscopy were in the range of $440 \mathrm{~nm}$, TEM micrograph showed spherical shape for the particles and zeta potential showed formation of negative charged nanoparticles with an average size of about $105.8 \mathrm{~nm} .1635 .41$ and $3249.83 \mathrm{~cm}^{-1}$ are the peaks detected from the FTIR analysis. In this study, biosynthesized silver nanoparticles mediated by C. comosum were tested for their antimycotic activity using a well diffusion method against fungal species; Aspergillus flavus, Penicillium sp, Fusarium oxysporum. Our findings indicated that biosynthesized AgNPs showed an efficient antimycotic activity against tested species. The antimycotic action of AgNPs varied according to different fungal species. Results confirmed the ability of C. comosum green shoot extract to act as an reducing and stabilizing agent during the synthesis of AgNPs.
\end{abstract}

Keywords: AgNPs; Antimycotic; Calligonum comosum; TEM; SEM; Zeta potential; FTIR

\section{Introduction}

Applications of nanoparticles (NPs) in the field of nanomedicine have been well documented recently. Therapeutic application to target definite sites, such as lung tissue, vaccinations and cancer therapy were recently employed [1]. Currently, the increasing use of NPs in medicine is closely associated with its potential to overcome microbial resistance. Furthermore, to circumvent the microbial resistance, NPs were used in a form of metallic NPs, chitosan NPs and nitric oxidereleasing NPs [2]. Among the metallic NPs, AgNPs possess excellent antibacterial, antifungal and antiviral potentials [3]. Several hypotheses have been suggested for the antibacterial mechanisms of AgNPs. (1) The surface-area-to-volume ratio increases in the smaller size material compared with the bulk material, which might provide opportunities for interactions 
with bacteria cell [4]. (2) AgNPs can cause cell lysis, inhibit cell transduction, changes in the cell membrane permeability and destruction of microbial genome and DNA fragmentation $[5,6]$. (3) AgNPs attach the surface of the cell membrane, penetrating in bacteria and disturb the cell function [7]. (4) AgNPs might modulate the phosphor tyrosine profile of treated bacterial peptides which affect cellular signaling that leads to inhibition of bacterial growth [8]. (5) It was observed that silver nanoparticles inhibit the formation of microbial biofilm which is an efficient barrier against the host immune system and antimicrobial agents [9]. (6) Through destruction of membrane integrity AgNPs exerted potent antifungal effects on fungi [10]. The author further postulated that, AgNPs is able to saturate and cohere to fungal hyphal cell which leads to deactivation of plant pathogenic fungi. Exact mechanism for the antimicrobial of NPs is not clearly known; nevertheless, it was suggested that electrostatic attraction between a negatively charged cell membrane and the positively charged NP, could be a good evidence for the significant antimicrobial action of NPs. Conversation of Ag ions to AgNPs by sodium borohydride as chemical reducing agent is widely applied [11]. Furthermore, hazardous chemical residues in the final product may cause potential environmental [12]. Compared to the use of hazardous chemicals as a tradition for this process, green synthesis is arising as an environmentally-friendly technique for biosynthesis of AgNPs. Recently, bacteria, fungi or plant parts such as leaves, fruits, and flowers beside pure compounds from plants, algae, carbohydrates, and microorganisms utilized for the biosynthesis of NPs [4, 13]. In phytonanosynthesis, biochemical diversity of plant extract, non-pathogenicity, low cost and flexibility in reaction parameters are accounted for high rate of AgNPs production with different shape, size and applications [14]. Phytochemicals such as terpenoids, flavones, ketones, aldehydes, amides and carboxylic acids in addition to plant-derived polysaccharides play dual roles as reducing and stabilizing agents [15]. Polysaccharides have hydroxyl groups, a hemiacetal reducing end, which is oxidized to carbonyl group beside other functionalities can play important roles in both the reduction and the stabilization of metallic NPs [16]. Using plant extracts bacteria, fungi, actinomycetes, yeast, algae for the biosynthesis of nanoparticles was reported [17]. A recent review revealed that using plant extract as abio-mediator for silver nanoparticles is faster than using microbes
[5]. Plants and natural resources such as Aloe vera, Ziziphus spina-christ and Eucalyptus camaldulensis, Moringa oleifera, tea, Catharanthus roseus and Chrysanthemum morifolium Ramat have been used for the synthesis of silver nanoparticles in addition to the application of the bio-prepared material on different types of microorganisms confirming the antimicrobial ability for this NPs [18-24]. In the present investigation Calligonum comosum was used as biomediater for AgNPs formation. Arta, Calligonum comosum L'Her. belongs to the family of the Polygonaceae. Woody based ascending shrub, glabrous much branched, straight up to $250 \mathrm{~cm}$ high, older branches rigid with whitish gray bark and swollen knotty nodes, young shoots green flexible 1-2 $\mathrm{mm}$ in diameter, branching and angled at nodes. Leaves minute, soon deciduous and usually absent. It is a plant of tropical and subtropical regions. Frequent in deeper sand, dunes, plains and valleys; cultivated around desert plantations as wind breaks; tolerates saline conditions. $<$ http:// www.haad.ae/HAAD/LinkClick.aspx?fileticket $=\mathrm{Sr} 3 \mathrm{tj}$ eg $5 \mathrm{xvo}=\&$ tabid $=791>$. It is a plant with a wide spread in Saudi Arabia. Anthraquinones and flavonoids are the major antioxidant constituents in Arta which had cytotoxic effect $[25,26]$. A recent studies demonstrated the antibacterial and antifungal ability of different plant parts of C. comosum [27-29]. Lack of information regarding $C$. comosum as a bio material for silver nanoparticles formation encourages us to use this plant types for the present investigation. In the present work C. comosum green shoots extract was used to mediate reduction of the $\mathrm{Ag}^{+}$present in the form of aqueous solution of silver nitrate to AgNPs. The main objective was to evaluate its antimycotic impact on some fungal species. To realize that goal inhibition zone was assessed.

\section{Materials and Methods Materials}

Arta, Calligonum comosum green shoots were collected from Riyadh, Saudi Arabia. Silver nitrate $\left(\mathrm{AgNO}_{3}\right)$ and Sabouraud Dextrose Agar (SDA) were purchased from (Wateenalhyaa company, Riyadh, Saudi Arabia) for the antimycotic assays.

\section{Biosynthesis of silver nanoparticles (AgNPs)}

The aqueous extract of $C$. comosum prepared by mixing $10 \mathrm{~g}$ of the dry sample with $100 \mathrm{ml}$ of highly purified water. The mixture was heated for 10 mins 
at $80{ }^{\circ} \mathrm{C}$ to denature the enzymes of the extracts. The solution was filtered through a Whatman filter paper No. 1 (pore size $125 \mu \mathrm{m}$ ). The supernatant (filtrate) was further filtered through a Whatman filter paper No. 1 (pore size $25 \mu \mathrm{m}$ ) to remove the residues. For synthesis of the AgNPs, $12 \mathrm{ml}$ of aqueous C. comosum extracts as reducing agents was mixed with $88 \mathrm{ml}$ of $1 \mathrm{mM}$ $\mathrm{AgNO}_{3}$ solution in an Erlenmeyer flask and allowed to react at room temperature. Ultra-high purity water was used as a reaction medium to avoid the presence of chloride ions and also to prevent precipitation of silver chloride. The AgNPs extract was stored at $4{ }^{\circ} \mathrm{C}$ until further analysis [19].

\section{Characterization of AgNPs}

The reduction of silver ions to AgNPs in the solution was monitored by measuring the ultraviolet-visible spectrum of the solution using a UV 2450 doublebeam spectrophotometer (Shimadzu, Tokyo, Japan) operated at a resolution of $2 \mathrm{~nm}$ in the range from 400$500 \mathrm{~nm}[19]$.

\section{Transmission electron microscopy (TEM)}

JEOL microscope (JEM-1011) was applied to determine AgNPs size, shape and morphology. Images were obtained at a $80 \mathrm{kV}$ voltage. Ag NPs' drop on the carbon-coated copper of the TEM grids after drying under vacuum and then loaded on the sample holder.

\section{Transmission electron microscopy (TEM) and scanning electron microscopy (SEM)}

SEM technique (Quanta 250, FEI) was applied to confirm AgNPs size, shape and morphology. Images were obtained at $10 \mathrm{kV}$.

\section{Dynamic light scattering (DLS) and zeta potential measurements}

Dynamic light scattering (DLS) and zeta potential measurements for the biogenic AgNPs were assessed using Zetasizer, Nano series, HT laser, ZEN 3600 (Malvern Instruments Ltd., Malvern, UK). A range between 0.1 and $10,000 \mathrm{~nm}$ was applied.

\section{Fourier transform infrared spectroscopy (FTIR)}

A range of 500 to $5000 \mathrm{~cm}^{-1}$ FTIR (Shimadzu FTIR Prestiage 21) was used for the biogenic AgNps. The biomolecules that act as reducing, capping, and stabilizing agent of the AgNps were recorded using diffuse reflectance mode.

\section{Evaluation of antimycotic activity of AgNPs}

The antimycotic activity of the synthesized AgNPs was measured using the well diffusion methods. Three fungal species were obtained from the biology laboratory, Faculty of Science, PNU. Selected fungal pathogens are commercially important and cause various diseases on vegetables, fruits, and crop plants. Stock cultures of Aspergillus flavus, Penicillium $s p$, Fusarium oxysporum were prepared and sub cultured in Sabouraud Dextrose Agar (SDA) slants at $4{ }^{\circ} \mathrm{C}$. Each strain was swabbed uniformly onto individual agar plates using sterile swabs. Subsequently, four adequately spaced wells (holes) of $4 \mathrm{~mm}$ diameter reach were made per plate at the culture agar surface using sterile metal cup borer. In each hole, $0.2 \mathrm{ml}$ of each biosynthesized AgNPs extract and $\mathrm{AgNO} 3$ were put under aseptic conditions, kept at room temperature for one hour to allow the extracts to diffuse into agar medium and incubated accordingly. Sterile distilled water was used as the reference negative control. All the plates were incubated at $25{ }^{\circ} \mathrm{C}$ for 48 hours. The plates were examined for sign of zone of inhibition, which appear as a clear space around the wells. The diameter of inhibition zones was measured using a ruler. Experiments performing in four replicates. Mean value was calculated.

\section{Statistical analysis}

All results were computed and expressed as mean \pm standard deviation (SD) from four replicates. Statistical analysis was performed using JMP software (version18.0) with analysis of variance (One-Way ANOVA).

\section{Results}

Using C. comosum as a reducing and a stabilizing bio-agent for silver nanoparticles formation was the principle aim of the current investigation besides, antifungal effect against some fungal species (Aspergillus flavus, Penicillium sp, Fusarium oxysporum) was tested for the bio-prepared AgNPs. Amount of $12 \mathrm{ml}$ of plant extract with the concentration of $1 \mathrm{mg} / \mathrm{ml}$ showed an ability to convert the colour of silver nitrate $1 \mathrm{M}$ from yellow to a dark brown colour (Fig. 1). The intensity of the brown color increased with an increasing in the incubation period of the 


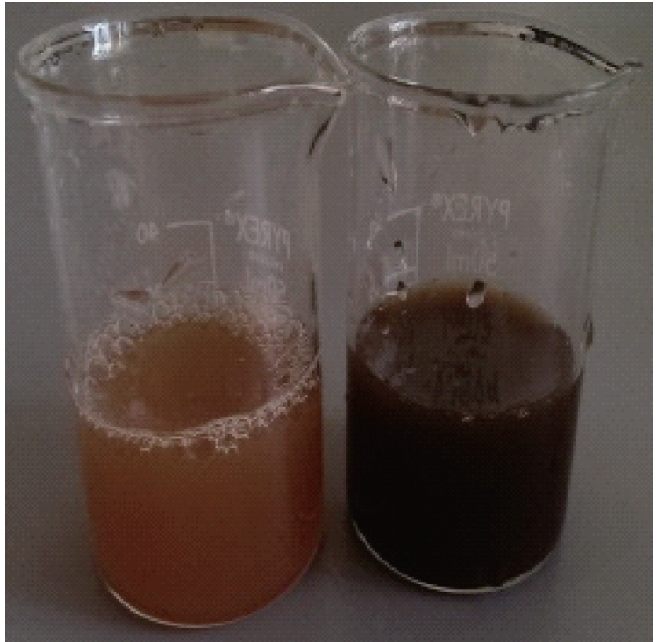

(a)

(b)

Fig. 1 Synthesis of AgNPs by $C$. comosum shoot extract. The figure shows (a) $C$. comosum extract and silver nitrate; and (b) $C$. comosum extract and silver nitrate after 2 hours. It was observed that the color of the solution turned to brown dark, indicating the formation of AgNPs.

mixture. Further confirmation of silver nanoparticles formation is the using of UV-Vis spectroscopy. The plasmon absorption bands of silver nanoparticles formed had an absorbance peak around $440 \mathrm{~nm}$. TEM image confirmed the development of Ag nanostructures with different sizes by using C. comosum and well indicated that the bio-prepared AgNPs are spherical in shape with a smooth surface morphology (Fig. 2). SEM image shows the morphologies of the biogenic synthesized nanoparticles at two magnifications (Fig. 3) confirming the spherical shape of the particles. Furthermore, dynamic light scattering of AgNPs biosynthesized by $C$. comosum showed an average size of $105.2 \mathrm{~nm}$ (Fig. 4). Zeta potential graph showed the potential stability of the particles in the solution. Negative charge of the nanoparticles $-6.62 \mathrm{mV}$ was well confirmed in this study for the plant-synthesized

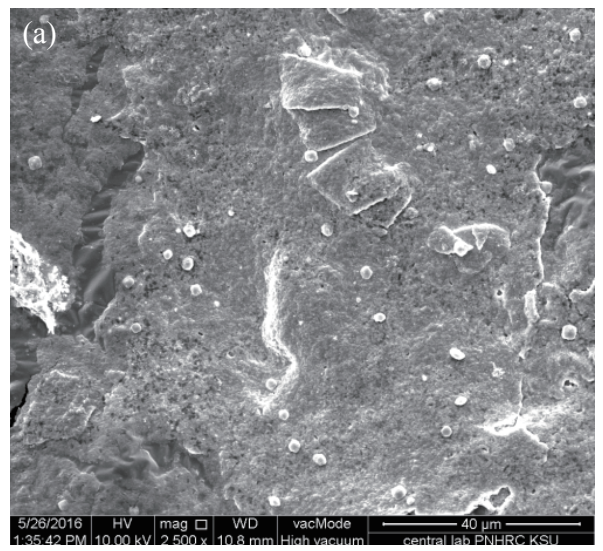

AgNPs (Fig. 5). FTIR spectra of the biogenic AgNPs showed two peaks located at 1635.41 and 3249.83 $\mathrm{cm}^{-1}$ (Fig. 6). Color change, spectrophotometer, TEM and SEM images, zeta potential and FTIR results revealed that, stable AgNPs can be easily produced when $C$. comosum aqueous extracts used as reluctant an stabilizing agent. Treatment of fungi with silver nitrate solution showed (10.5-14.0 $\mathrm{mm}$ ) range of inhibitory zone confirming the ability of silver nitrate to suppress the fungal growth (Table 1). Moreover, Silver nanoparticles (AgNPs) synthesized by $C$. comosum showed an antifungal ability indicated by an inhibition zone against Aspergillus flavus (19.5 \pm 0.9 $\mathrm{mm})$ as the highest zone compared with other tested species, Penicillium sp $(18 \pm 1.2 \mathrm{~mm})$ and Fusarium oxysporum $(16 \pm 0.7 \mathrm{~mm})$ Table 1 . AgNPs had higher ability to suppress the fungal growth compared with silver nitrate solution.

\section{Discussion}

Recently, development of a new antimicrobial

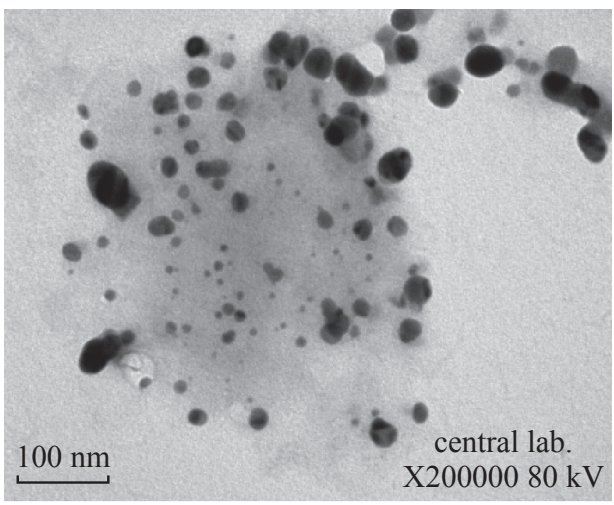

Fig. 2 Transmission electron microscopy (TEM) images indicating shape, morphology and size for AgNPs synthesized from C. comosum shoot extract. Scale bar $=100 \mathrm{~nm}$.

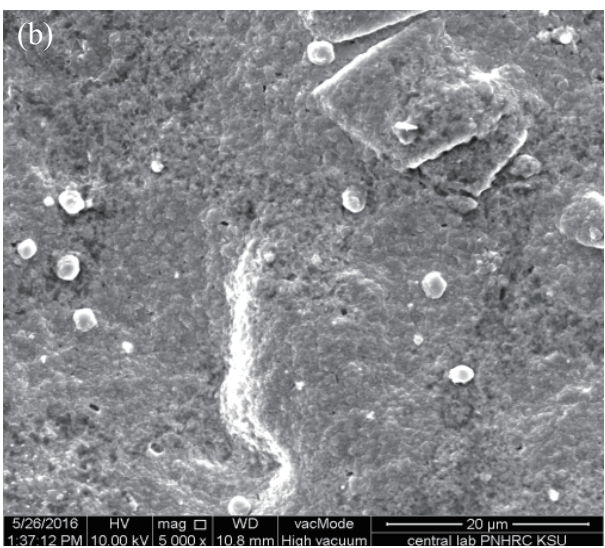

Fig. 3 Scanning electron microscope (SEM) image showing spherical shape of silver nanoparticles synthesized from $C$. comosum shoot extract at different magnifications: (a) $2500 \mu \mathrm{m}$; (b) $5000 \mu \mathrm{m}$. 
Size (d.nm) Intensity (\%) St Dev (d.nm)

$\begin{array}{rllll}\text { Z-Average (d.nm): } 105.8 & \text { Peak 1: } & 134.2 & 100.0 & 60.10 \\ \text { Pdi: } 0.200 & \text { Peak 2: } & 0.000 & 0.0 & 0.000 \\ \text { Intercept: } 0.870 & \text { Peak 3: } & 0.000 & 0.0 & 0.000\end{array}$

Result quality: Good

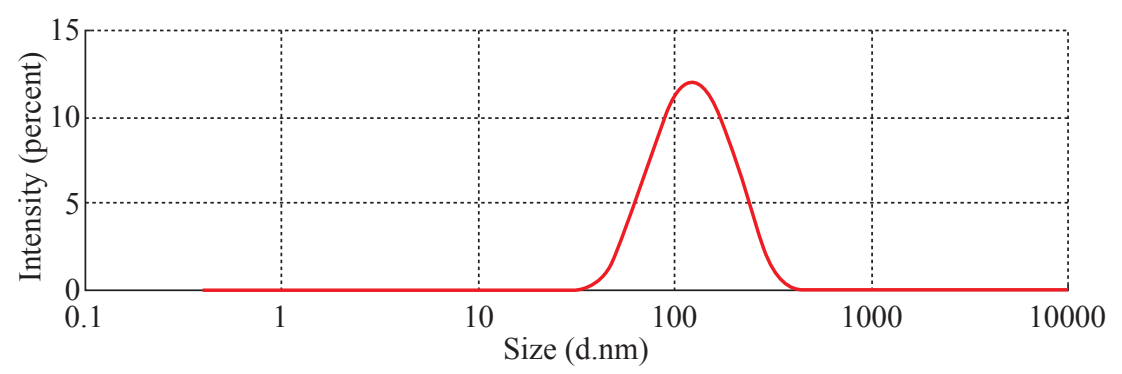

Fig. 4 Zitasizer for AgNPs synthesized from C. comosum shoot extract.

Mean (mV) Area (\%) St Dev (mV)

$\begin{array}{ccccc}\text { Zeta potential }(\mathrm{mV}):-6.62 & \text { Peak 1: } & 31.1 & 69.1 & 18.6 \\ \text { Zeta deviation }(\mathrm{mV}): 111 & \text { Peak 2: } & -131 & 7.0 & 9.03 \\ \text { Conductivity }(\mathrm{mS} / \mathrm{cm}): 4.38 & \text { Peak 3: } & -103 & 4.1 & 7.28\end{array}$

Conductivity (mS/cm): $4.38 \quad$ Peak 3: $\quad-103 \quad 4.1 \quad 7.28$

Result quality: See result quality report

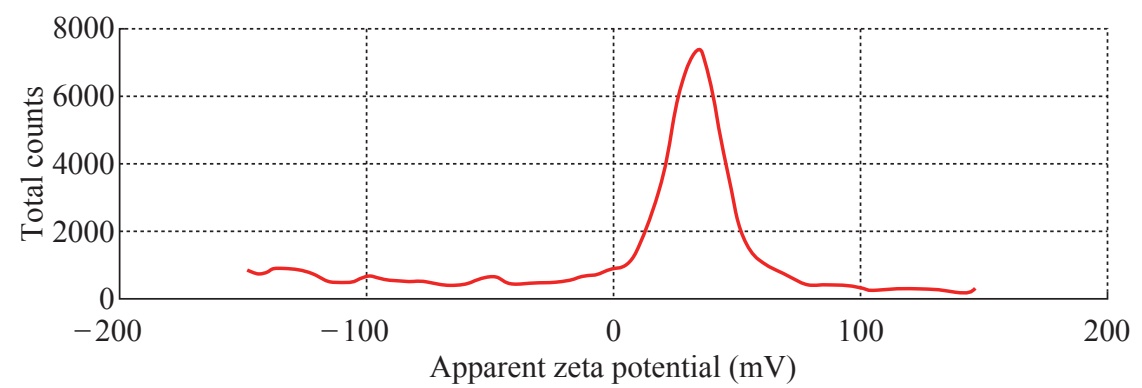

Fig. 5 Zeta potential graph of AgNPs prepared from the C. comosum shoot extract.

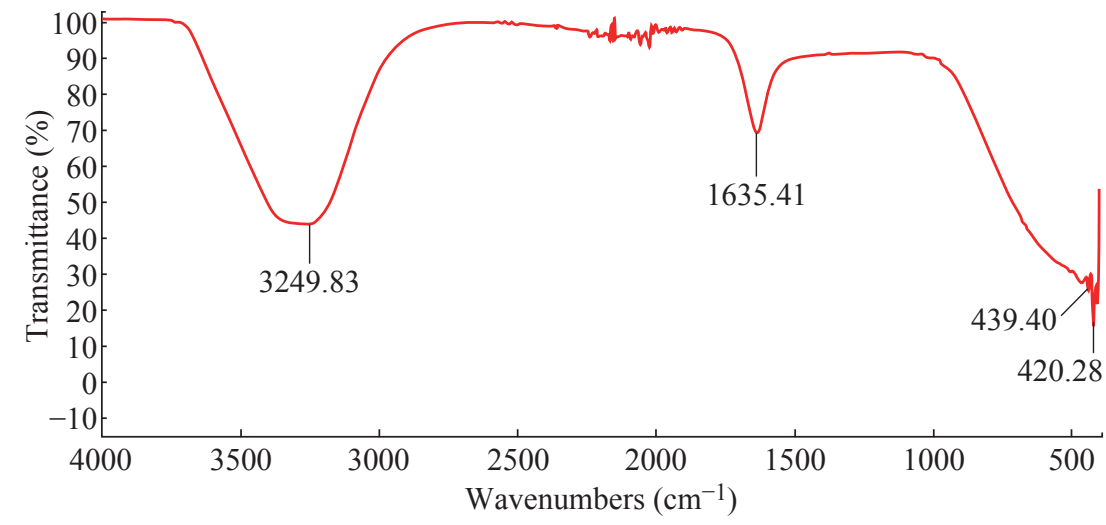

Fig. 6 FTIR spectrum recorded for biogenically synthesized AgNPs prepared from the C. comosum shoot extract.

Table 1 Inhibition zone (mm) of fungi treated with AgNPs synthesized by C. comosum shoot extract. Data are expressed as mean \pm $\mathrm{SD}$ of four replicates. Different letters within a raw indicate significant differences in the Tukey test; $\alpha=5 \%$.

\begin{tabular}{|c|c|c|c|}
\hline Treatment & Aspergillus flavus & Penicillium sp. & Fusarium oxysporum \\
\hline $\begin{array}{l}\text { AgNPs (Silver nanopartices } \\
\text { mediated C. comosum) }\end{array}$ & $19.5 \pm 0.9 \mathrm{a}$ & $17 \pm 1.2 \mathrm{ab}$ & $15 \pm 0.7 \mathrm{~b}$ \\
\hline $\mathrm{AgNO}_{3}$ & $14 \pm 1 \mathrm{a}$ & $12.5 \pm 0.5 \mathrm{ab}$ & $10.5 \pm 0.5 \mathrm{~b}$ \\
\hline
\end{tabular}


compounds has proved to be efficient in suppressing microorganisms and thus widely employed in medical field as a reliable alternative for antibiotics to which certain microbes have developed a relative resistance. Silver and Klasen [30, 31]. demonstrated that, there is a serious medical need for antibiotics with novel antimicrobial mechanisms because fungi are eukaryotic organisms with a metabolism and construction that are similar to those of eukaryotic hosts (plant, animal and human). Silver nitrate is known for its antimicrobial ability against bacteria and fungi. Interestingly, silver nanoparticles is found to be more efficient in mitigating the effect of harmful microbes compared with other forms of silver compounds. The present study was firstly aimed to evaluate the capacity of $C$. comosum as a reducing and a stabilizing bio-agent for AgNPs formation. A further goal was to study the ability of the biosynthesized silver nanoparticles with respect to their antifungal effect against some fungal species (Aspergillus flavus, Penicillium sp, Fusarium oxysporum). C. comosum extract showed an ability to convert the extract of silver nitrate to dark colour in 2 hours which is an indication for the conversion of silver nitrate to silver nanoparticles. The colour changes are acquired due to the excitation of SPR in the synthesized NPs [32]. Time needed for the conversion of Ag ions to NPs was differ according to the type of plant extract used since Ocimum sanctum extract have taken $1 \mathrm{~h}$, Azadirachta indica and $P$. nigrum leaf and stem extracts show the formation of brown color in 10 mins [32-34]. UV-Vis spectroscopy in this study confirmed silver nanoparticles formation since abroad absorption peak ranging from 400-450 $\mathrm{nm}$ is a characteristic band for the $\mathrm{Ag}$, arising from the excitation of longitudinal plasmon vibrations of AgNP in the solution [35]. On the other hand, TEM images results were well documented by the observations recorded by Singh et al; Heydari and Rashidipour $[36,37]$. when AgNPs prepared by Oak fruit hull. Using biogenic material for AgNPs formation is an uncontrolled process provides wide range of particle size [38] this might indicate why AgNPs are variable in size in this study (Fig. 2). AgNPs were enclosed to a thin layer of organic material (carbon) which is providing its stability by acting as capping agent [39]. Relatively spherical shaped silver nanoparticles were also detected by Krithiga et al and Banerjee et al. [40, 41], where Clitoria ternatea and banana extracts were used as bio-mediator in silver nanoparticle formation respectively, and SEM images were recorded. A range between 50 to $300 \mathrm{~nm}$ particle size of the synthesized silver nanoparticles using red apple fruit extract was obtained [42], which is in line with our results of dynamic light scattering AgNPs biosynthesized by $C$. comosum. Zeta potential graph showed the potential stability of the nanoparticles in the solution since negative charge was detected [43]. Similar trend of observations was also recently reported by Singh et al. [36], where silver nanoparticles were synthesized from P. amarus and T. cordifolia. On the other hand, color change, spectrophotometer, zeta potential, TEM and SEM results revealed that stable AgNPs with variability in size can be easily produced by $C$. comosum aqueous extracts. Such methods might be a feasible, low-cost and environmentally friendly technique. C. comosum produce a unique secondary metabolites such as Anthraquinones, flanovonids and dehydrodicatechin which had cytotoxic effect and antioxidant activity $[25,26]$. These compounds might be the main reason for the reduction process of silver nitrate to silver nanoparticles since the plant secondary metabolites can act for reduction/ oxidation reactions in the bio-synthesis of silver nanoparticles [5]. Reducing and stabilizing agents for silver nanoparticles were detected by the FTIR spectra. Peaks located at $1635.41 \mathrm{~cm}^{-1}$ which might be due to the presence of a primary amine $\mathrm{NH}$ band. Absorbance between 1600 and $1700 \mathrm{~cm}^{-1}$ can indicate the amide I vibration for proteins which might be due to the $\mathrm{C}=\mathrm{O}$ stretching vibration [45]. The absorption peak at $1635.41 \mathrm{~cm}^{-1}$ is near to that reported for natural proteins [46]. This evidence suggest that proteins are interacting with biosynthesized nanoparticles were not affected during reaction with $\mathrm{Ag}+$ ions or after binding with Ag nanoparticles [47]. Furthermore, peak at $3249.83 \mathrm{~cm}^{-1}$ could be due to $\mathrm{O}-\mathrm{H}$ groups of phenolic compounds. These results confirm the presence of proteins and phenolic compounds which may act as reducing and stabilizing agents for the biogenic AgNPs. Furthermore, AgNPs had higher ability to suppress the fungal growth compared with silver nitrate, this might be due to the larger surface areas of the nanoparticles which increased the interaction zone with biological targets. Similar observations regarding a potent antifungal activity of biosynthesized AgNPs were also demonstrated against $C$. albicans and Saccharomyces cerevisiae [48] and against Aspergillus niger, Candida albicans and Candida parasilopsis [49]. Furthermore, inhibitory effects of phytosynthesized AgNPs aginst Aspergillus $s p$ and Fusarium $s p$. was 
well detected $[10,50]$. Different antifungal ability regarding the biogenic AgNPs might be associated with the characteristics of certain species which was also documented by many different studies [48, 49]. It has been hypothesized that silver nanoparticles can cause cell lysis, inhibit cell transduction, changes in the cell membrane permeability and probably destruction of fungal membrane integrity besides, AgNPs penetrate in the fungi cell that lead to cell death through stop cell division $[5,10,48,51]$. Furthermore, AgNPs is able to saturate and cohere to fungal hyphal cell which leads to deactivation of plant pathogenic fungi beside Complexes of the bases contained in DNA with $\mathrm{Ag}^{+}$ is a powerful inhibitor of fungal DNAases [10, 52]. The antimicrobial action of AgNPs is well correlated with its decreased size and shape having increased surface area that lead to superior antimicrobial action. Furthermore, the biosynthesis rate of AgNPs from plant origin is an ecofriendly method that is costless with no toxic chemicals.

\section{Conclusions}

In summary, AgNPs exerted potent antimycotic effects on fungi tested in vitro, probably through destruction of membrane integrity. Further study is needed to maintain the adequately required concentrations for use, with careful handling of this nanotechnology; AgNPs can be a good friend for the betterment of human life and the environment at large.

\section{Acknowledgements}

The author would like to thank the Prof. Jehan Albrahim, Department of Biology, Faculty of Science, Princess Nourah bint Abdulrahman University for the nice comments throughout the experimental period of this study.

\section{Conflict of Interest}

The authors declare that they have no conflict of interest.

\section{References}

[1] A.J. Thorley, T.D. Tetley, New perspectives in nanomedicine. J Pharm Thera. 2013, 140: 176-185.

[2] R.Y. Pelgrift, A.J. Friedman, Nanotechnology as atherapeutic tool to combat microbial resistance. Adv. Drug Deliv. Rev., 2013, 65: 1803-1815.
[3] C.A. dos Santos, M.M. Seckler, A.P. Ingle, et al., Silver nanoparticles: therapeutical uses, toxicity and safety issues. J Pharm Sci, 2014, 103: 1931-1944.

[4] Y. Park, New paradigm shift for the green synthesis of antibacterial silver nanoparticles utilizing plant extracts. Toxicol Res, 2014, 30: 169-178.

[5] S. Prabhu, E.K. Poulose, Silver nanoparticles: mechanism of antimicrobial action, synthesis, medical applications, and toxicity effects. International Nano Letters, 2012, 2: $1-10$.

[6] S.M. Ouda, Some nanoparticles effects on Proteus sp. and Klebsiella Sp. isolated from water. Am J Infect Dis microbiol, 2014, 2: 4-10.

[7] J.R. Morones, J.L. Elechiguerra, A. Camacho, et al., The bactericidal effect of silvernanoparticles. Nanotechnology, 2005, 16: 2346-2353.

[8] S. Shrivastava, D . Dash, Agrifood nanotechnology: living revolution in food and agriculture. $J$ Nanotech, 2009, 12: 240-243.

[9] S.L. Percival, P.G. Bowler and J. Dolman, Antimicrobial activity of silver containing dressings on wound microorganisms using an in-vitro biofilm model. Int Wound J, 2007, 4:186-191.

[10] S.W. Kim, J.H Jung, 1. K. Lamsa, et al., Antifungal effects of silver nanoparticles (AgNPs) against various plant pathogenic fungi. Mycobiology, 2012, 40: 53-58.

[11] M. Yamanaka, K. Hara and J. Kudo, Bactericidal actions of a silver ion solution on Escherichia coli, studied by energy-ltering transmission electron microscopy and proteomic analysis. Appl Environ Microbiol, 2005, 71: $7589-7593$.

[12] G. Geoprincy, B.N.V. Srri, U. Poonguzhali, et al., A review on green synthesis of silver nanoparticles. Asian $J$ Pharm Clin Res, 2013, 6: 8-12.

[13] R. Mie, M.W. Samsudin, L.B. Din, et al., Synthesis of silver nanoparticles with antibacterial activity using the lichen Parmotrema praesorediosum. Int J Nanomed, 2014, 9: 121-127.

[14] H.P.Borase, B.K. Salunke , R.B Salunkhe, et al., Plant extract: a promising biomatrix for ecofriendly, controlled synthesis of silver nanoparticles. Appl. Biochem Biotechnol, 2014, 173: 1-29.

[15] A.K. Jha, K. Prasad and A.R. Kulkami, Plant system: nature's nanofactory. Colloids Sur B: Biointerfaces, 2009, 73: 219-223.

[16] Y. Park, Y.N. Hong, A. Weyers, et al., Polysaccharides and phytochemicals: a natural reservoir for the green synthesis of gold and silver nanoparticles. IET Nanobiotechnol, 2011, 5: 69-78.

[17] K.N. Thakkar, S.S. Mhatre and R.Y. Parikh, Biological synthesis of metallic nanoparticles. Nanomedicine, 2010, 6: 257-262.

[18] S.P. Chandran, M. Chaudhary, R. Pasricha, et al., Synthesis of gold nanotriangles and silver nanoparticles using Aloe vera plant extract, Biotechnol Prog, 2006, 22: 577-583.

[19] A.E. Mohammed, Green synthesis and antimicrobial activity of Eucalyptus camaldulensis mediated silver nanoparticles. Asian Pac J Trop Biomed, 2015, 5(5): 382386.

[20] A.E. Mohammed, J.S. Albrahim, Synthesis, characterization and evaluation of antimicrobial potency of silver nanoparticles using ZiziphusSpina-christi L. leaf extract. J Pure Appl Microbiol, 2014, 8: 3903-3908.

[21] T.N. Prasad, E.K. Elumalai, Biofabrication of Agnanoparticles using Moringa oleifera leaf extract and theirantimicrobial activity. Asian Pac J Trop Biomed, 2011, 1: 439-442.

[22] B. Vaseeharan, P. Ramasamy and J.C. Chen, Antibacterial activity of silver nanoparticles (AgNps) synthesized by 
tea leaf extracts against pathogenic Vibrio harveyi and its protective efficacy on juvenile Feneropenaeus indicus. Lett. Appl. Microbiol, 2010, 50: 352-356.

[23] K.S. Mukunthan, E.K. Elumalai, T.N. Patel, et al., Catharanthus roseus: a natural source for the synthesisof silver nanoparticles. Asian Pac J Trop Biomed., 2011, 1: 270-274.

[24] Y. He, Z. Du, H. Lv, et al., Green synthesis of silver nanoparticles by Chrysanthemum morifolium Ramat. extract and their application in clinical ultrasound gel. Int J Nanomed, 2013, 8: 1809-1815.

[25] S.A. Ghazanfar, Ed., Handbook of Arabian medicinal plants. CRC Press, 1994: 272.

[26] M. Kamil, A.F. Jayaraj, F. Ahmad, et al., Pharmacognostic and phytochemical standardisation of Calligonum comosum. J Pharm Pharmacol, 2000, 52 (Suppl): 262.

[27] A. Chouikh, M. Mekki and E.H. Adjal, Effects of extraction methods on antibacterial activity of different extracts of Calligonum comosum L'Her. Growing in sahara Algerian. Int J Recent Sci Res, 2015, 6: 3534-3536.

[28] D.H.M. Alkhalifa, In-vitro antibacterial activity of ethanol extract of Calligonum comosum plant against four human pathogens in Saudi Arabia. Int J Plant, Animal Env Sci, 2013, 3: 170-175.

[29] J.S. Al-Abrahim, A.E. Mohammed and M.M. Elobeid. Assessment of in-vitro anti-fungal potential of ethanolic extract of Cologonum cosomum against two fungal postharvest pathogens of fruits and vegetables in Saudi Arabia. Int J Appl Biol Pharm, 2013, 590-594.

[30] S. Silver, Bacterial silver resistance: molecular biology and uses and misuses of silver compounds. FEMS Micro Rev, 2003, 27: 341-353.

[31] H.J. Klasen, A historical review of the use of silver in the treatment of burns. II. Renewed Interest for Silver. Burns, 2000, 26: 131-138.

[32] K. PaulKumar, G. Gnanajobitha, M. Vanaja, et al., Piper nigrum leaf and stem assisted green synthesis of silver nanoparticles and evaluation of its antibacterial activity against agricultural plant pathogens. Sci world J. 2014, 2014: Article ID 829894, 9 pages.

[33] C. Ramteke, T. Chabarti, B.K. Sarangi, et al., Synthesis of silver nanoparticles from aqueous extract of leaves of Ocimum sacnctum for enhanced antimicrobial activity. Journal of Chem. 2013, 2013: Article ID 278925, 7.

[34] S.S. Shankar, A. Rai, A. Ahmad, et al., Rapid synthesis of Au, Ag, and bimetallic Au core Ag shell nanoparticles using Neem (Azadirachta indica) leaf broth, J Colloid Interface Sci, 2004, 275: 496-502.

[35] Y. Chen, C. Wang, Z. Ma, et al., Controllable colours and shapes of silver nanostructures basedon $\mathrm{pH}$ : application tosurface-enhanced Ramanscattering. Nanotechnology, 2007, 18: 325-602

[36] K. Singh, M. Panghal, S. Kadyan, et al., Evaluation of antimicrobial activity of synthesized silver nanoparticles using Phyllanthus amarus and Tinospora cordifolia Medicinal Plants. J Nanomed Nanotechnol, 2014, 5: 250.

[37] R. Heydari, M. Rashidipour, Green synthesis of silver nanoparticles using extract of oak fruit hull (Jaft): synthesis and in vitro cytotoxic effect on MCF-7 cells. Int J Breast Cancer, 2015, 2015: Article ID 846743, 6.

[38] A.M. Elgorban, A.N. Al-Rahmah, S.R. Sayed, et al., Antimicrobial activity and green synthesis of silver nanoparticles using Trichoderma viride. Biotechnol Biotechnol Equip, 2016, 30(2): 299-304.

[39] A. Vivek, K. Jitendra, S. Ritu, et al., Green synthesis of silver nanoparticles by Trichoderma harzianum and their bioefficacy evaluation against Staphylococcus aureus and Klebsiella pneumonia. Ind Crops Products, 2014, 55: 202-206.

[40] N. Krithiga, A. Rajalakshm and A. Jayachitra, Green synthesis of silver nanoparticles using leaf extracts of Clitoria ternatea and Solanum nigrum and study of its antibacterial effect against common nosocomial pathogens. J Nanosci, 2015, 2015: Article ID 928204, 8.

[41] P. Banerjee, M, Satapathy, A. Mukhopahayay, et al., Leaf extract mediated green synthesis of silver nanoparticles from widely available Indian plants: synthesis, characterization, antimicrobial property and toxicity analysis. Bioresour Bioprocess, 2014, 1: 3.

[42] S.A. Umoren, I.B. Obot and Z.M. Gasem, Green synthesis and characterization of silver nanoparticles using red apple (Malus domestica) fruit extract at room temperature. J. Mater Environ Sci, 2014, 5(3): 907-914.

[43] G.R. Reddy, A.B. Morais and N.N. Gandhi, 2,2-Diphenyl1-Picrylhydrazyl free radical scavenging assay and bacterial toxicity of protein capped silver nanoparticles for antioxidant and antibacterial applications. Asian $J$ Chem, 2013, 25(16): 9249-9254.

[44] M.R. Karekal, V. Biradar and M.B.H. Mathada, Synthesis, characterization, antimicrobial, DNA cleavage, and antioxidant studies of some metal complexes derived from schiff base containing indole and quinoline moieties. Bioinorg Chem Appl, 2013, 2013: Article ID 315972, 16.

[45] J. Kong, S. Yu, Acta. fourier transform infrared spectroscopic analysis of protein secondary structures. Biochim Biophys Sin, 2007, 39(8): 549-559.

[46] I.D.G. Macdonald, W.E. Smith, Orientation of cytochrome $\mathrm{C}$ adsorbed on a citrate-reduced silver colloid surface. Langmuir, 1996, 12: 706-713.

[47] A.M. Fayaz, K. Balaji, M. Girilal, et al., Biogenic synthesis of silver nanoparticles and their synergistic effect with antibiotics: a study against gram-positive and gram-negative bacteria Nanomed. Nanotechnol Biol Med, 2010, 6(1): 103-109.

[48] A. Nasrollahi, K. Pourshamsian and P. Mansourkiaee, Antifungal activity of silver nanoparticles on some of fungi. Int J Nano Dimens, 2011, 1 (3): 233-239.

[49] D.J. Saraniya, B.B. Valentin, Antibacterial and antifungal activity of silver nanoparticles synthesized using Hypnea muciformis. Biosci Biotechnol Res Asia, 2014, 11: 235238.

[50] V.R. Pasupuleti, T.N.V.K.V. Prasad, R.A. Shiekh, et al., Biogenic silver nanoparticles using Rhinacanthus nasutus leaf extract: synthesis, spectral analysis, and antimicrobial studies. Int J Nanomedicine, 2013, 8: 3355-3364.

[51] V. Alt, T. Bechert, P. Steinrucke, et al., An in-vitro assessment of the antibacterial properties and cytotoxicity of nanoparticulate silver bone cement. Biomaterials, 2004, 25: 4383-4391.

[52] W.J.A. Ghandour, J. Bubard, M.N. Deistung, et al., The uptake of silver by Escherichia coli $\mathrm{K} 12$ toxic effect and interaction with copper. Appl. Microbiol. Biotechnol, 1988, 28: 559-565.

Copyright ${ }^{\circ} 2016$ Afrah E. Mohammed. This is an open-access article distributed under the terms of the Creative Commons Attribution License, which permits unrestricted use, distribution, and reproduction in any medium, provided the original author and source are credited. 